\title{
A four-year eddy-permitting assimilation of sea-surface temperature and altimetric data in the South Atlantic Ocean
}

\author{
by Thierry Penduff ${ }^{1}$, Pierre Brasseur ${ }^{1}$, Charles-Emmanuel Testut ${ }^{1}$, \\ Bernard Barnier ${ }^{1}$ and Jacques Verron ${ }^{1}$
}

\begin{abstract}
Sea-surface temperature (SST) and sea-surface height (SSH) data are assimilated with a reducedorder sequential filter every 10 days over four years (1993-1996) in a 1/3-degree resolution South Atlantic primitive equation model. At every assimilation step, the misfit between observations and their model counterparts is evaluated and projected onto the dominant 10 multivariate, full-depth local modes of variability diagnosed from a free model run (without assimilation). Satellite observations are used to perform a sequential update of all model variables according to their "natural" correlations with the surface variables. In this paper, we perform a validation of both the mean state and the eddy flow. Over the four years of assimilation, the forecast-data RMS misfit is decreased (i) by $55 \%$ on SSH; (ii) by $40 \%$ on SST; (iii) by about $20 \%$ on temperature in the upper $700 \mathrm{~m}$ with regard to independent, synoptic XBT data; (iv) as deep as $3500 \mathrm{~m}$ on the time-averaged temperature distribution compared to a recent climatology. These statistical estimates of the assimilation performance were complemented by a more original oceanographic investigation that revealed a significant improvement in the mean circulation (in particular in the Confluence region and in the deep ocean), the position of the main fronts, the averaged level and basin-scale distribution of SSH variance, the detailed evolution of individual mesoscale structures, the vertical distribution of the eddy kinetic energy, and the salinity field. These results would further be improved by the assimilation of in-situ data below sharp thermoclines that tend to decorrelate subsurface dynamics from the observed surface.
\end{abstract}

\section{Introduction}

Satellite measurements of sea-surface temperature (SST) and sea-level anomalies (SLA) provide oceanographers with a real-time monitoring of the surface state of the world ocean. They also highlight the need for a better knowledge of other crucial surface variables (salinity, absolute velocities) and of subsurface processes. The combined use of highresolution numerical ocean models and advanced data assimilation methods constitutes a physically-consistent way to interpolate this valuable but incomplete surface dataset in time, to extrapolate the surface information toward the ocean depths, and to learn about 
nonobserved dynamical variables, as recommended in the AIMS (Analysis, Interpretation, Modeling and Synthesis) phase of the WOCE program. Reliable three-dimensional, multivariate model-data syntheses are also required for the initialization of oceanic prediction systems.

Our goal is to produce a consistent picture of the mean state and variability in the South Atlantic Ocean through the assimilation into a numerical model of sea-surface height (SSH) and SST data based on observations. The aim of this paper is to estimate the impact of assimilation on the mean oceanic state and the eddy flow, not only from the usual statistical indexes, but also from direct comparisons of the solution with independent information such as transport estimates, circulation patterns, or current meter data.

The South Atlantic Ocean is connected to the North Atlantic, the Pacific, the Indian and the Antarctic oceans. These sub-basins mostly interact in localized and eddy-active regions of the South Atlantic. For example, the eddies produced in the confluence region of the Malvinas and Brazil currents mix Subantarctic waters with Atlantic waters, and the eddies produced in the Agulhas Current are responsible for a large part of Indian-Atlantic exchanges. A numerical model able to resolve the mesoscale dynamics and to represent the thermodynamics of water masses properly is required to simulate these processes. The assimilation method should also be able to control the highly nonlinear eddy field and to extrapolate surface data toward the subsurface and nonobserved variables in accordance with the local dynamics and stratification.

In the present study, the impact of data assimilation is evaluated from a statistical point of view (model-data misfits), and from an oceanographic point of view. Since the available independent synoptic XBT data are too sparse below the surface in the South Atlantic to perform an accurate validation, we will also compare our solution to a long-term T-S climatology, current meter data, circulation schemes, and in-situ transport estimates. Section 2 describes the model configuration, the assimilation method, the assimilated dataset and the experimental design. The impact of assimilation is presented in Section 3, both statistically and physically, for observed and nonobserved variables. A summary of the results and a conclusion is given in Section 4.

\section{Numerical model and assimilation method}

\section{a. Model configuration and forcing}

The geopotential-coordinate primitive equation model used in this study is OPA8.1 (Madec et al., 1998) in a configuration derived from the Clipper Atlantic 1/3-degree experiment (Tréguier et al., 1999). The model is therefore "eddy-permitting": it cannot represent mesoscale features very accurately without assimilation. However, a high vertical resolution (42 levels) was chosen to simulate subsurface processes, to represent surface-subsurface covariances correctly, and to achieve a good extrapolation of surface data toward the ocean depths.

In the present application, the computational domain (Fig. 1) is limited by three 


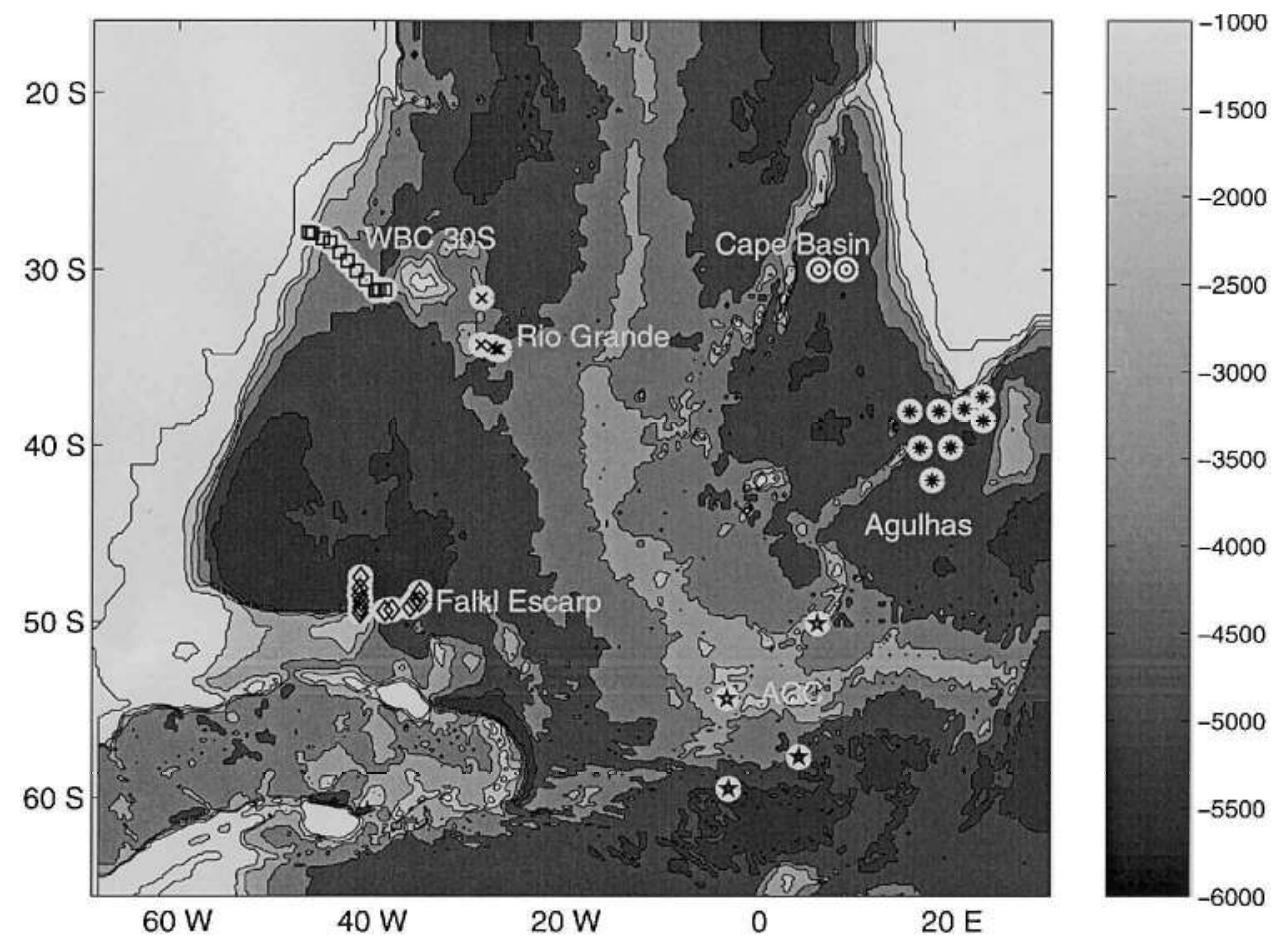

Figure 1. Model bathymetry; contours every $1000 \mathrm{~m}$. Marks show the location of the WOCE current meters used to validate the eddy kinetic energy field in Section $3 \mathrm{~d}(\mathrm{ii})$.

open-active boundaries at 68W (Drake Passage), 30E (Africa to Antarctica), and 16S (Brazil to Angola). The Weddel Sea is not included in the domain because no altimeter data is available there. Along the closed southern boundary (65.8S), the model temperatures and salinities are relaxed within a 2.4-degree-wide buffer zone toward the Reynaud et al. (1998) seasonal climatology (hereafter referred to as RLMB) interpolated at each timestep. The three open boundaries radiate outgoing perturbations away and relax model fields toward the RLMB seasonal climatology interpolated at each timestep. The topography was interpolated from the 1/12-degree Smith and Sandwell (1997) database on the 1/3-degree model grid. Vertical mixing is achieved by a prognostic TKE closure model (Blanke and Delecluse, 1993), reinforced by convective adjustment in the case of static instability. A 140-Sv Antarctic Circumpolar Current (ACC) is forced through the meridional boundaries and a zero net transport is prescribed across $16 \mathrm{~S}$. Details of the model configuration are provided in Penduff et al. (2001).

The model is started from rest on the fourth of June, 1988, with temperature and salinity fields initialized from the RLMB climatology interpolated at this date. The daily surface forcing (wind stress, heat flux, and evaporation minus precipitation) is taken from the ECMWF atmospheric reanalysis. The heat flux is corrected by a relaxation of model SSTs 
toward reference values (weekly SSTs, Reynolds and Smith, 1995) that mimics the negative feedback of SST on the heat flux (Barnier, 1998). ECMWF evaporation minus precipitation fields were converted into equivalent salt fluxes, which are similarly corrected by restoring model sea-surface salinities (SSS) toward reference RLMB values. Surface fluxes and reference SST/SSS fields are interpolated at each timestep. The relaxation terms are applied in the same fashion with and without assimilation to keep the model forcing method unchanged. It seems a priori that this choice may induce a competition during the assimilation run between the fields to which model SSTs are relaxed and those which are assimilated. However, the relaxation terms primarily act on surface tracer fields on timescales of 45 to 65 days (increasing poleward), which are much longer than the duration of the assimilation cycle (10 days), whereas assimilation instantaneously affects all model variables over the whole water column every 10 days. SST assimilation is thus expected not to be adversely affected by the relaxation of SST.

\section{b. Data assimilation method and assimilated dataset}

i. Method. Satellite data is assimilated sequentially. A series of correction/prediction cycles is carried out to fit the model trajectory to the data. The state vector of the problem is composed of all prognostic variables of the primitive equation model, i.e. the barotropic streamfunction, and the three-dimensional fields of horizontal velocity, temperature, and salinity.

For linear systems, the optimal combination between model and observed data can be obtained with the Kalman filter, which consistently takes into account the balance between the confidence in the model prediction and the accuracy of the observed quantities (Kalman and Bucy, 1961; Gelb, 1974). However, a full Kalman filter cannot be implemented because of the amount of computation required by the error propagation equation, and also because of the lack of knowledge of prescribed error statistics. An interesting approach consists of approximating the evolution equation for the prediction error by computing its asymptotic limit in a reduced space [Fu et al., 1993; Fukumori and Malanotte-Rizzoli, 1995]. In the present implementation, we consider a static error covariance matrix estimated from statistics of the model variability. This hypothesis makes the assimilation scheme sub-optimal, but the nonlinearities of the model equations and the size of the numerical system would make an optimal treatment practically impossible in any case.

As in the reduced-order Kalman filter introduced by Pham et al. (1998), the background error is expressed by means of a limited number of three-dimensional, multivariate, empirical orthogonal functions (EOFs) describing the dominant modes of the system variability,

$$
\mathbf{P}=\mathbf{S}^{T} \boldsymbol{\Lambda}^{-} \mathbf{S},
$$

where $\mathbf{S}$ is a simplification operator (of dimension $r \times n$ ) related to the $r$ EOF directions $\{\mathbf{S}\}_{\mathbf{k}}$ of the error sub-space, and $\mathbf{\Lambda}^{-}$is related to their amplitude. The analysis equations are those derived for the SEEK filter described in several earlier publications (Pham et al., 
1998; Verron et al., 1999; Brasseur et al., 1999). The reduced-rank approximation allows the update of the state vector to be written as:

$$
x_{i}^{a}=x_{i}^{f}+\mathbf{K}\left[y_{i}-\mathbf{H}\left(x_{i}^{f}\right)\right]
$$

with the gain matrix $\mathbf{K}$ expressed in terms of the simplification operator $\mathbf{S}$ :

$$
\mathbf{K}=\mathbf{S}^{T}\left[\left(\boldsymbol{\Lambda}^{-}\right)^{-1}+\mathbf{S} \mathbf{H}^{T} \mathbf{R}^{-1} \mathbf{H} \mathbf{S}^{T}\right]^{-1} \mathbf{S} \mathbf{H}^{T} \mathbf{R}^{-1} .
$$

The forecast state vector (of dimension $n$ ) obtained by model integration up to timestep $i$ is noted $x_{i}^{f} ; x_{i}^{a}$ is the state vector after the analysis step, and $y_{i}$ is the vector of observed quantities of dimension $p$ (in our case study, maps of SST and sea-surface height). The observation operator $\mathbf{H}$ is of dimension $p \times n$ and relates the data to the model variables, and $\mathbf{R}$ is the observation error covariance matrix (which is diagonal here). The assimilation cycle is completed with a 10-day forecast, using the non-linear model $\mathbf{M}$ initialized with the updated state:

$$
x_{i+1}^{f}=\mathbf{M}\left\{x_{i}^{a}\right\}
$$

A key-point of the method is the three-dimensional, multivariate nature of the analysis, which is essential to project the information from the observed quantities to the whole state vector (i.e. to specify how satellite observations of the sea-surface are used to correct the subsurface and non-observed ocean variables). Combining (2) and (3), the correction of the forecast can further be expressed as a weighted combination of the $r$ error modes:

$$
x_{i}^{a}=x_{i}^{f}+\mathbf{S}^{\mathbf{T}} \mathbf{w}
$$

with

$$
\mathbf{w}=\mathbf{\Lambda}^{+} \mathbf{S} \mathbf{H}^{\mathrm{T}} \mathbf{R}^{-1}\left[y_{i}-\mathbf{H}\left(x_{i}^{f}\right)\right]
$$

and

$$
\boldsymbol{\Lambda}^{+}=\left[\left(\boldsymbol{\Lambda}^{-}\right)^{-1}+\mathbf{S H}^{T} \mathbf{R}^{-1} \mathbf{H} \mathbf{S}^{T}\right]^{-1}
$$

The truncation of the EOF analysis of the free run (without assimilation) variability determines the dimension of the inverse (7) that must be computed at each analysis step. In the present application, we determined empirically that the first 10 EOFs were appropriate to reduce the cost of the analysis sufficiently while preserving enough degrees of freedom to correct the model state. The error of the analysed state vector is equal to:

$$
\mathbf{P}^{a}=\mathbf{S}^{T} \boldsymbol{\Lambda}^{+} \mathbf{S}
$$

Eq. (8) expresses the error reduction due to the addition of new information into the system: the error decreases as a function of the accuracy (i.e., $\mathbf{R}^{\mathbf{1}}$ ) and quantity (i.e., dim H) of observations available at each analysis cycle. In the present study, the error statistics were kept constant (equal to $\mathbf{P}$ ) during the assimilation experiment. 
ii. Local assimilation procedure. A new algorithmic feature has been introduced in this experiment to increase the impact of the data on the control of the mesoscale circulation. Instead of considering global EOFs, as was done in similar reduced-rank assimilation problems (e.g. Verron et al., 1999), we compute local EOFs from the full model state vector variability over independent, full-depth, $2 \times 2$-gridpoint square sub-systems. The analysis step is performed using Eqs. (2) and (3) to update each group of 4 water columns, taking into account the SST/SSH observations available within $3 \times 3$-degree zones of influence centered on each sub-system. The influence of surface observations on each sub-system decreases with distance (through an exponential increase of the observation error variance) and is virtually nil at the limits of the zones of influence. Two neighboring sub-systems use almost the same local dataset because their zones of influence largely overlap each other. This ensures the continuity of the gain between adjacent subsystems and the smoothness of the correction at basin scale. In case of absence of data within a particular zone of influence, no correction is applied within the corresponding subsystem. The size of the boxes and zones of influence were determined empirically, in order to achieve the best possible control of the eddy activity.

Like so-called "optimal interpolation" schemes, our assimilation method is sub-optimal and makes use of fixed background error covariances. However, the use of spatiallydependent, tridimensional, multivariate statistics derived from a free model integration relates the present method to a simplified, reduced-order Kalman filter.

iii. Implementation and dataset. The local EOFs computed from the four-year free run are not expected to be trustworthy where threshold processes occur. Therefore, local EOFs were not computed (and no assimilation was performed) wherever ice was detected during the free model run. This southern region without assimilation was extended northward by 7 grid points to take into account the extent of the zones of influence. This area is represented in white along the southern boundary in Figure 2. To avoid interferences between the open boundary conditions and the assimilation, SST and SSH data were also masked along the domain limits. The white area in Figure 2 corresponds to the mask actually applied to SST data. In addition to this, SSH data were masked for areas shallower than $200 \mathrm{~m}$ because of the lack of accuracy of tidal and inverse barometer corrections in coastal zones. The area where SSH is actually assimilated is bounded by the black line in Figure 3. Only SSH is assimilated where and when clouds mask SST values, and only SST is assimilated where $\mathrm{SSH}$ is masked.

The time window chosen for the assimilation experiments extends from November 1992 to December 1996, i.e., a period for which both ECMWF reanalysis, SST and SLA data products are available simultaneously. The SST data consist of composite AVHRR observations, gathered and processed within the NASA Pathfinder project. In addition, these products have been quality controlled, compared with Reynolds analyses and gridded on maps at 1/4-degree resolution every 10 days as part of the European DIADEM project. AVHRR observations cover the entire model domain, but the presence of clouds, to some 




Figure 2. No assimilation is performed in the white area which includes the vicinity of the three open boundaries and the southernmost region (labeled ICE) where some ice is detected in the free run between 1993 and 1997. In addition, SSH data is not assimilated along the shallow part of the western boundary or east of $20 \mathrm{E}$ where no mean $\mathrm{SSH}$ data is available (see Figure 3). The performance of the assimilation procedure within the "CONFLUENCE," "SUBTROPICAL GYRE” AND “AGULHAS” regions is evaluated in Figure 4. See text for details.

extent, restricts the practical availability of SST data at high latitudes and during the winter season. An accuracy of $0.5 \mathrm{C}$ on the gridded SST products has been assumed, which corresponds to the sum of errors in acquisition procedures, processing algorithms and space/time interpolation. The assimilated altimetric dataset consists of 10-day SSH maps at the resolution of $1 / 4$ degree, obtained as the sum of a time-invariant dynamic topography, and SLA maps from the AVISO project. The gridded SLA fields at 1/4-degree resolution were calculated by combining TOPEX/Poseidon (T/P) and ERS altimeter data, and interpolating between tracks according to the method described by Le Traon et al. (1998) which minimizes the along-track ERS and T/P dual crossover differences and takes long wavelength errors into account. The uncertainty of the SLA products can be decreased to $3 \mathrm{~cm}$ on average because of an efficient correction of along-track orbit errors.

The mean SSH added to SLA maps is shown in Figure 3. It was derived by Le Grand (1998, personal communication) from inverse modeling of the Atlantic circulation at 1-degree resolution using the RLMB climatology as a dynamical constraint (see Le Grand et al., 2003). This mean SSH is representative of the large-scale, geostrophic circulation, and includes a representation of Ekman transports from ERS wind products. The use of climatological density data gives this field a smooth character, with the exception of a frontal structure around $(5 \mathrm{~W}, 45 \mathrm{~S})$. This artifact actually appears in the RLMB climatology used to constrain the inverse model probably because of a local lack of (or bias in) in-situ data (Le Grand, personal communication, 2002). This front does not seem realistic, especially since it is not associated with any topographic feature, and it will be shown that 


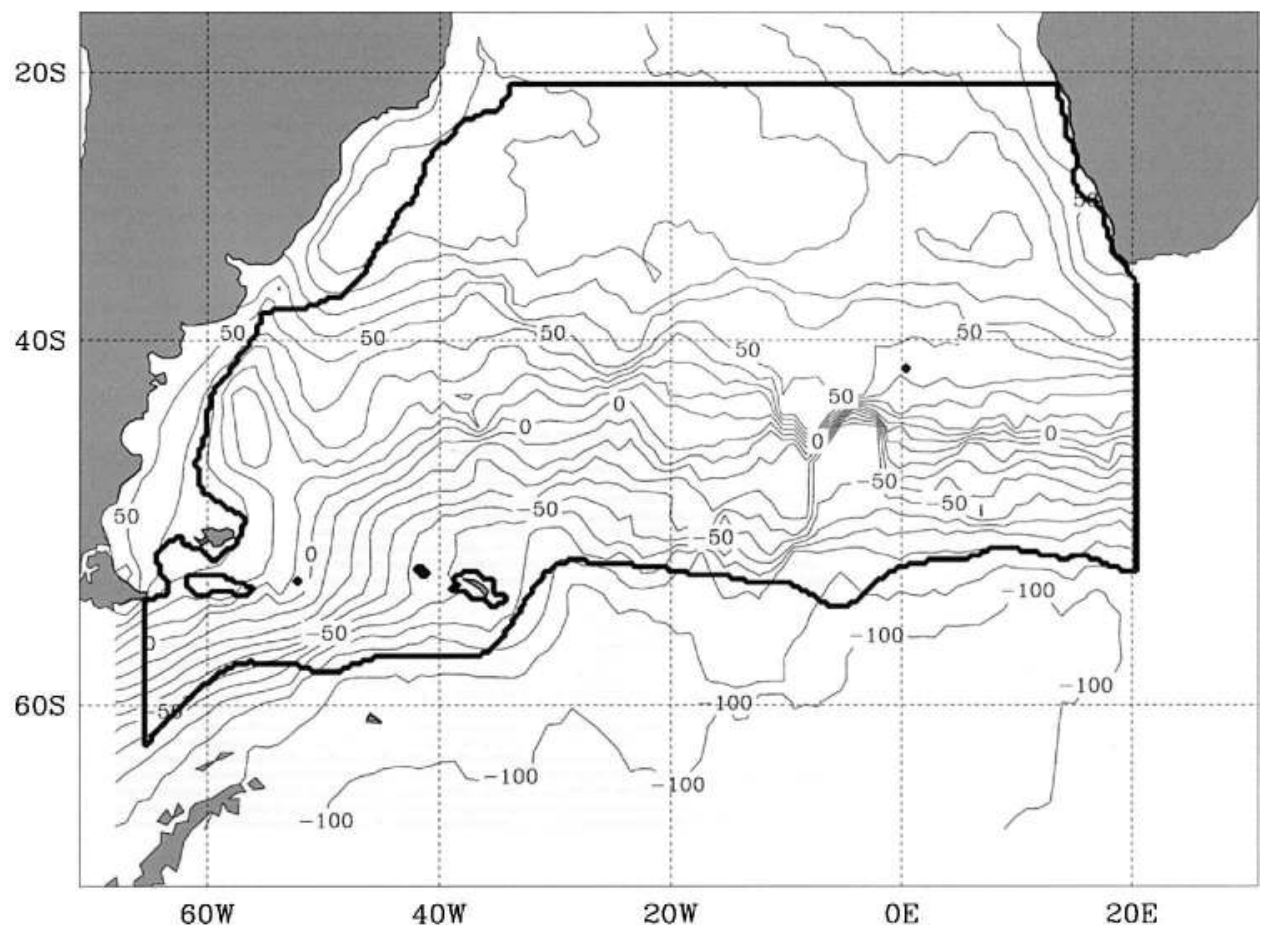

Figure 3. Mean SSH field $(\mathrm{cm})$ deduced from an inverse model (Le Grand, 1998, personal communication). This field was added to the Topex-Poseidon/ERS1-2 SLA dataset to build the $\mathrm{SSH}$ fields that are assimilated in the model. SSH is assimilated within the area limited by the black line.

it has a significant but local impact on the assimilation results. A bulk RMS error of $5 \mathrm{~cm}$ on the total SSH data has been prescribed in the assimilation system, taking into account the cumulated effect of measurements, inverse estimates, and mapping procedures.

\section{c. Experimental design}

The model was spun up from rest during 3.5 years (June 4, 1988 to December 11, 1991) forced by the ECMWF reanalysis at the surface. The integration was continued without assimilation (free run) until December 31, 1996 to build the EOF basis used in the filter. The model was then restarted on November 1, 1992 and integrated with assimilation. This run became statistically stable after about two months, and was continued until December 31,1996 . The assimilation run and free run are compared with one another over the same 4-year period. They will be compared with different types of data in the next section. The duration of the first two phases (spinup and free run) is justified hereafter.

The dominant 10 local modes of the model variability during the free run determine the quality of the full-depth, multivariate corrections performed during the assimilation run. 
Since these modes are largely affected by mesoscale turbulence, the eddy flow must be stabilized during the model spinup. Preliminary tests showed that it takes about 3 years from rest to obtain a globally stabilized eddy kinetic energy field, to stabilize the temperature and salinity drift triggered at start in the upper $800 \mathrm{~m}$, and to put surface fluxes, tracer distribution and circulation in mutual equilibrium over this depth range. The model was thus spun up for 3.5 years before the free run was started. This duration is too short to allow for a full-depth adjustment of the basin, but long enough to adjust the upper-layer ocean characteristics and short enough to avoid significant modifications of deep water masses during the spinup. The 4-year free run resolves the seasonal cycle properly. Model variables were saved every ten days during the free run to sample the mesoscale eddy field sufficiently and build an EOF base that adequately represents the statistics of the mesoscale and seasonal variability. The first ten local EOFs of this 4-year free run constitute the basis of the filter used for data assimilation.

\section{Impact of assimilation}

\section{a. Assimilated variables (SSH, SST) and main fronts}

i. Statistics. The RMS misfit between the assimilated data and their model counterparts is shown in Figure 4 for the free and assimilated runs in the regions shown in Figure 2. In the free run, the mean SST RMS error estimated over the whole assimilation region is about $1.8 \mathrm{C}$, ranging between 1 and $2.5 \mathrm{C}$ regionally. The amplitude of the seasonal cycle is about $25 \%$ of the mean misfit and its phase varies regionally. The SSH misfit remains close to $20 \mathrm{~cm}$ in the free run $(17 \mathrm{~cm}$ in the Subtropical Gyre, $30 \mathrm{~cm}$ in the more turbulent Confluence region). The assimilation system requires about 2 months of spinup after which it stabilizes: errors on the analysed and forecasted SSH/SST fields remain roughly constant. After each analysis step, the RMS misfit on SSH/SST is close to the prescribed observation error $(5 \mathrm{~cm} / 0.5 \mathrm{C})$ and increases up to $10 \mathrm{~cm} / 1 \mathrm{C}$ during forecasts. This systematic increase is primarily due to model and/or forcing errors, and to the local assimilation procedure since corrections are expected to be decorrelated in the horizontal at scales larger than the influence radii. A physical adjustment is thus expected, and occurs during the 10-day forecasts. With respect to the forecasts, the assimilation procedure thus performs a twofold decrease of the model-data misfit on the (surface) observed variables in the regions shown in Figure 2.

Our subsequent diagnostics will be focused on the series of forecasts ( $x_{f}$ fields) to illustrate the dynamics that are retained by the model after 10-day adjustments. In this study, we shall also restrict our analysis to the mean model fields and their annual variances averaged over the four years of assimilation.

ii. Physical fields. The SSH and SST model forecasts, averaged over the period 19931996, are now compared with their counterparts in the free run, with the assimilated SSH data, and with the SST field in the RLMB climatology. The time average of the assimilated 


\section{SST $\left({ }^{\circ} \mathrm{C}\right)$}
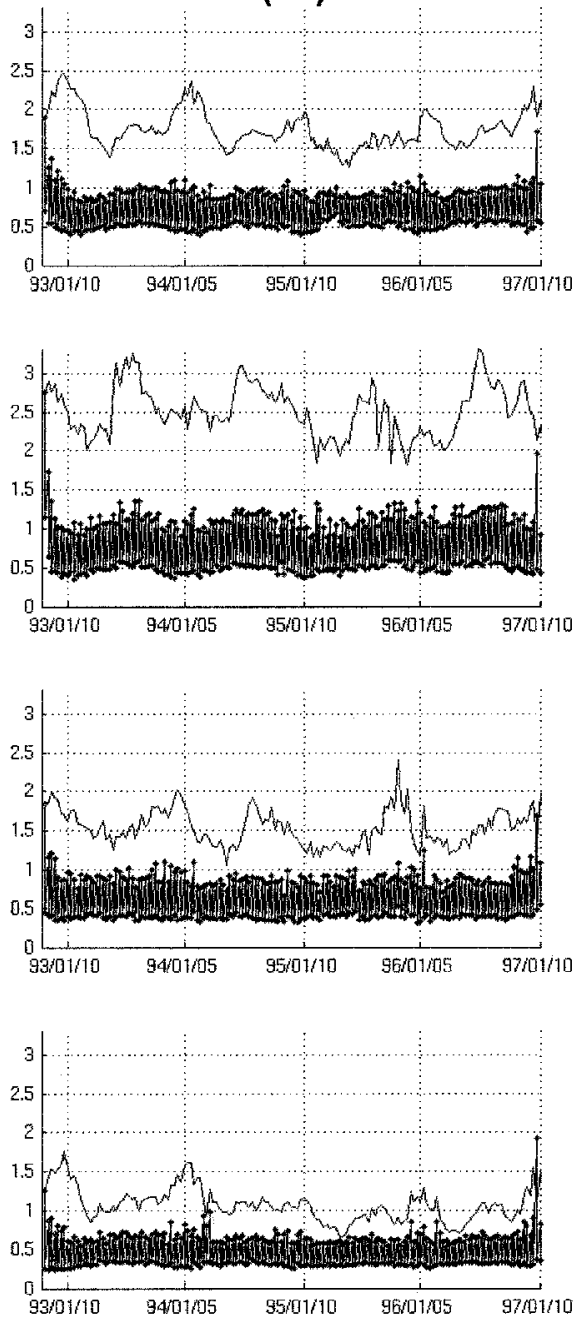

$\mathrm{SSH}(\mathrm{cm})$
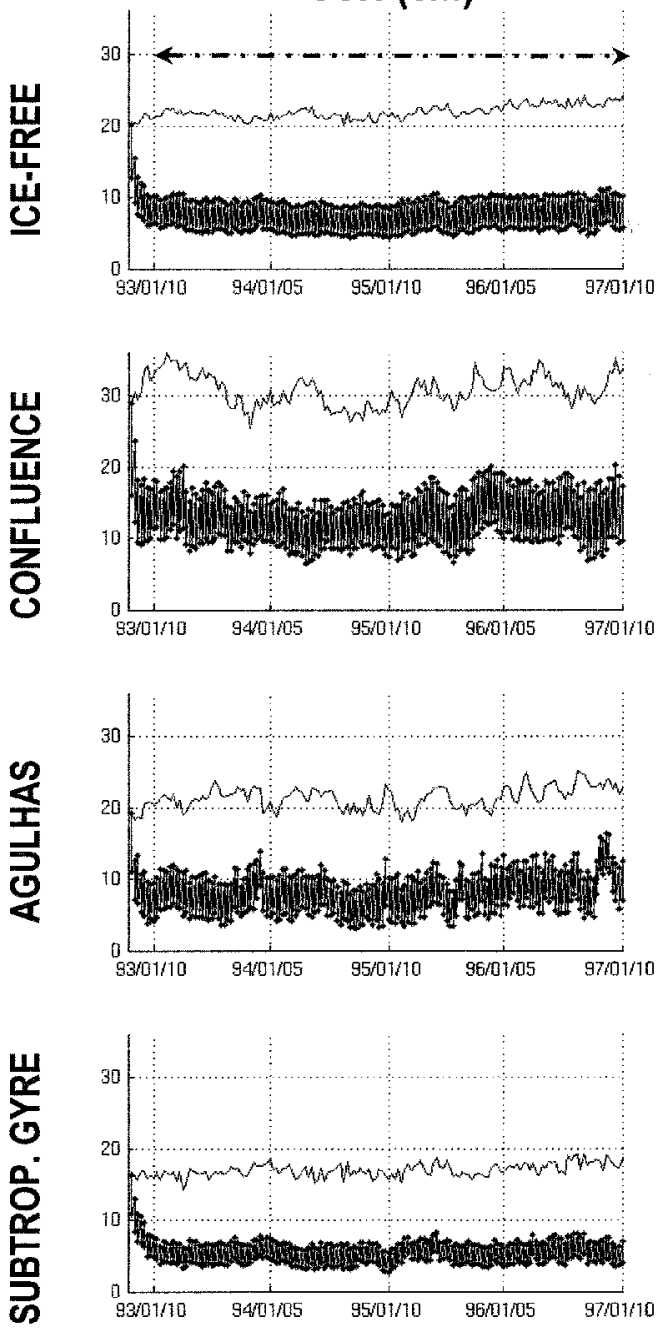

Figure 4. Time evolution of the basin-averaged RMS model-data misfit on SST (left panel) and SSH (right panel) in the regions shown in Figure 2. For each assimilated variable, the label "ICEFREE" refers to the area where assimilation is performed (shaded regions in Figure 2 for SST, region limited by the black line in Figure 3 for SSH). Upper and lower lines correspond to the free and assimilated run, respectively. Dates are indicated along the horizontal axis in format year/month/day. The thick dot-dashed line shown in the right-upper panel indicates the 4-year period over which our subsequent diagnostics are focused (12/31/1992-12/31/1996).

SST data was not computed since these fields exhibit gaps associated with clouds. Instead, the RLMB SST field was taken as a reference to validate the model SST. These time-averaged SSH and SST reference fields are presented in the middle panels of Figure 5. 


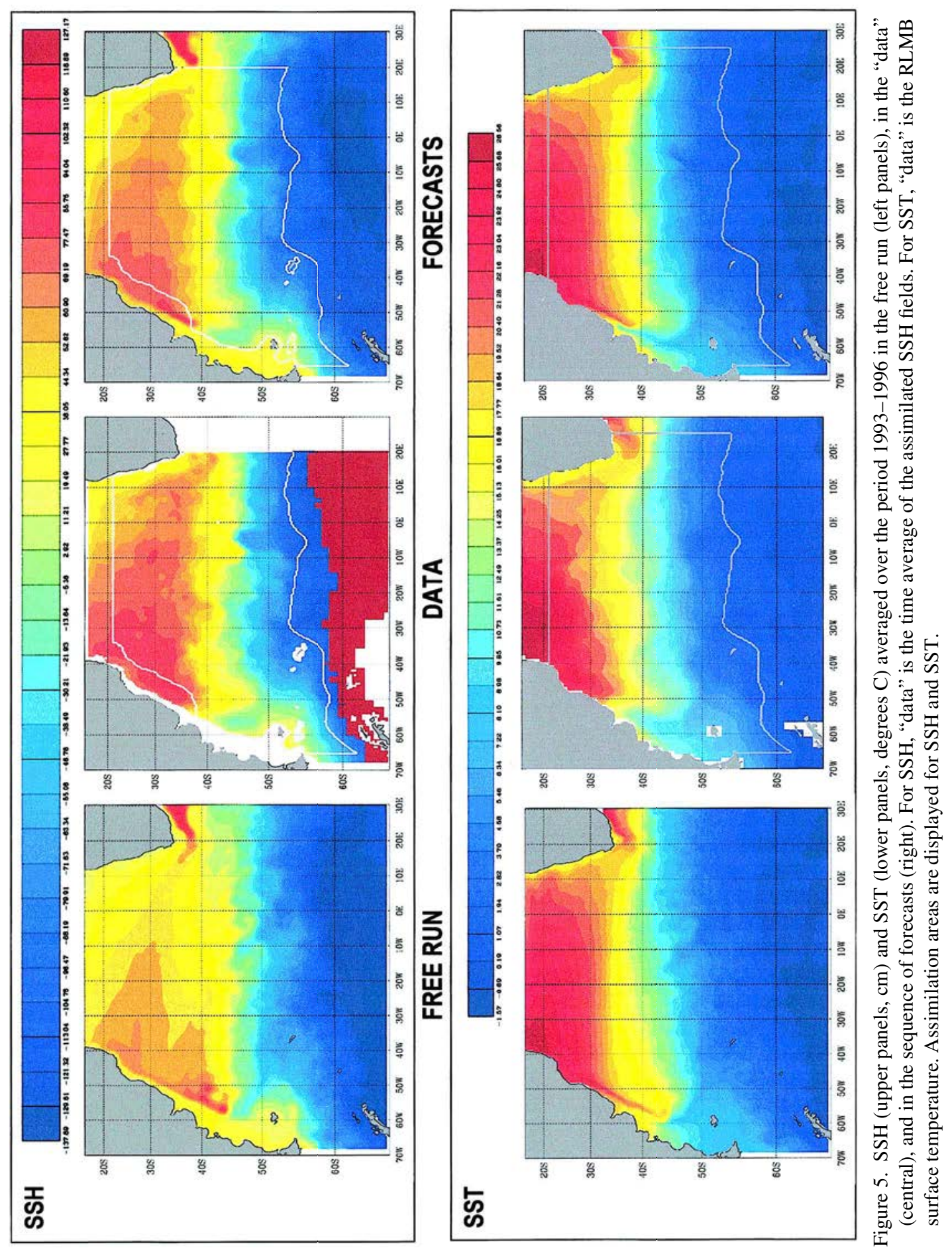



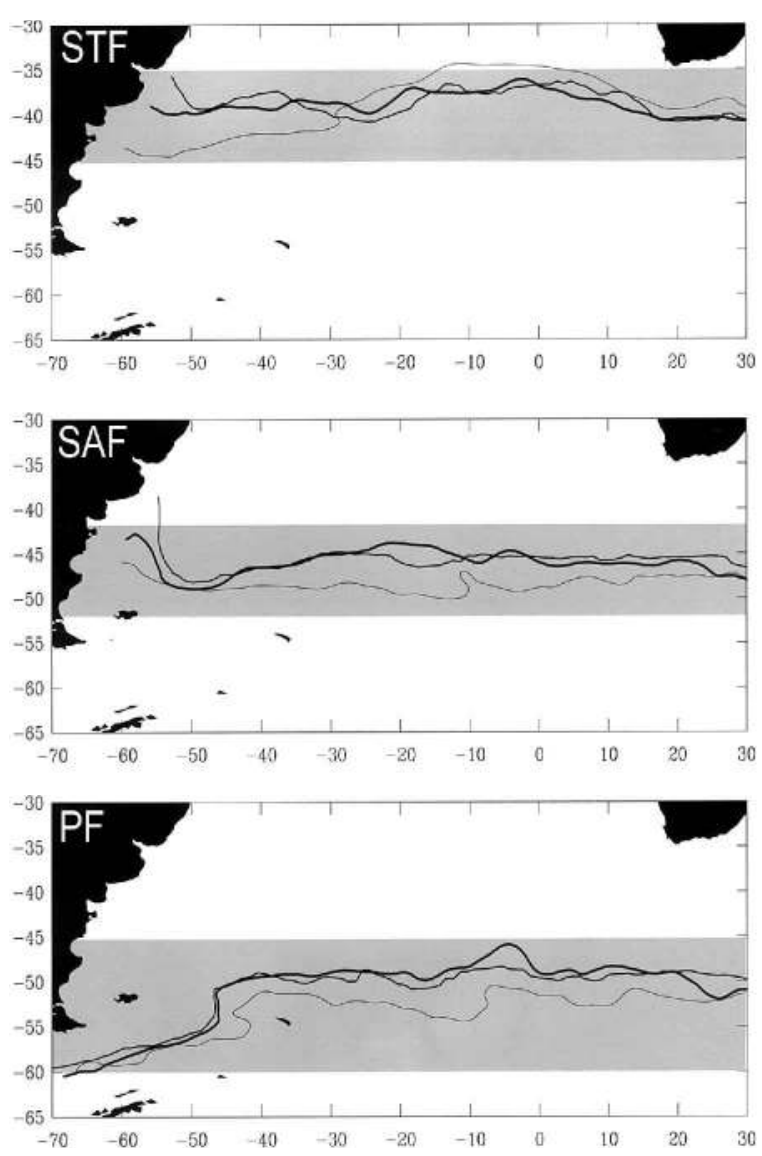

Figure 6. Mean positions of the Subtropical Front (STF, upper panel), Subantarctic Front (SAF, middle), and Polar Front (PF, lower panel) in the free run (thin line), the annual RLMB climatology (medium line), and the forecast sequence (thick line). STF, SAF and PF are identified at $200 \mathrm{~m}$ by $\mathrm{S}=35.0, \mathrm{~T}=5.0 \mathrm{C}$, and $\mathrm{T}=2.0 \mathrm{C}$ respectively. Model tracer fields have been averaged over 1993-1996. Shaded areas show the STF, SAF, and PF areas used for horizontal averaging in Figure 9.

Figure 6 shows the mean position of the three main fronts of the basin in the model and in the RLMB climatology at $200 \mathrm{~m}$. This climatological state should be compared with the model tracer fields with caution because of its smooth character, its lower resolution and its non-synopticity with the model solution, but is useful to estimate how the model fronts tend towards their climatological latitude at large scale. Snapshots of SSH are shown in Figure 7 and will be discussed below.

- Subtropical Gyre

The mean SSH fields (Fig. 5) show that the shape of the STG is more realistic (more 
rectangular) in the forecasts than in the free run. Indeed, the eastern limit of the gyre (Benguela Current) becomes more meridional, and, as shown below, its southern limit (the South Atlantic Current/Subtropical Front) becomes more zonal. The doming of the subtropical gyre and the associated bowling of the thermocline are also enhanced, showing that the transport of those currents, and of the Brazil Current, is increased by the assimilation. In the free run, the Agulhas Current retroflection apparently penetrates too far west into the South Atlantic (positive SSH anomaly in the upper left panel of Figure 5). This feature is the signature of the Agulhas Rings which tend to follow similar trajectories in this model without assimilation (Penduff et al., 2001, 2002). As shown below, this unrealistic tendency of the model, already noted in the FRAM experiments (Quartly and Srokosz, 1993), is removed by the assimilation procedure. The SST field is quite realistic north of $34 \mathrm{~S}$ in the free run. This can be seen in the lower panels of Figure 5 and in Figure 4 where the SST misfit is as low as 1C in the Subtropical Gyre in the free run (this is also the case below the surface, see section 3.2). The assimilation procedure therefore leads to relatively small corrections. The main discrepancy in the free SST in the subtropics is the absence of the basin-wide zonal gradient observed between 25 and $35 \mathrm{~S}$. This feature is partly reconstructed by the assimilation.

\section{- Confluence-Subtropical and Subantarctic Fronts}

RLMB (Fig. 5) and satellite SSTs show that the Malvinas Current (MC) brings cold waters northward along the western boundary up to about $38 \mathrm{~S}$, and steers sharply to the south along the southern flank of the warm Brazil Current (BC). The BC separates from the shelf around 37S. The complex interaction between the MC, the BC, the eddy flow and the topography in the Confluence region then gives birth to the Subtropical Front (STF) and the Subantarctic Front (SAF). In the Argentine basin, the SAF follows a wide anticyclonic loop that brings it southwards, away from the more zonal STF (Fig. 6).

This circulation pattern in the Confluence region is not well simulated without assimilation (Figs. 5 and 6). The $\mathrm{MC}$ and the $\mathrm{BC}$ collide along the shelf much too far south (around 44S) and form an eastward jet which then spreads out meridionally and forms the STF and SAF. In the free run, these two fronts are located too close to each other and several degrees away from their climatological location in the Argentine Basin (Fig. 6). As expected from the conservation of potential vorticity, the STF in the free run undergoes a strong shift northwards along the western flank of the MidAtlantic Ridge (MAR), also visible on the SSH field, and continues its eastward course about 3 degrees north of its climatological position. In a similar way, the SAF is locally deviated above the crest of the MAR, but remains 3-4 degrees south of its climatological position until it leaves the basin.

In the assimilation run, the cold waters advected by the $\mathrm{MC}$ attain a more realistic latitude (36S, see Fig. 5). The BC does not overshoot unrealistically to the south along the shelf but separates from it at this latitude. The STF is shifted to the north by 
3-4 degrees west of $30 \mathrm{~W}$ and to the south elsewhere, bringing it close to its climatological latitude. The better location of the STF (identified by the 35.0 isohaline) in this area shows that the non-observed salinity field is improved below the surface (see also section 3.2). In the assimilation run, west of $42 \mathrm{~W}$, the SAF and STF remain slightly (1 degree) south of their climatological positions, but their relative position is much more consistent with the climatology. As in the free run, the SAF (better located with assimilation) is shifted northwards above the MAR. This deflection is surprisingly absent from our climatological tracer fields, but in accordance with potential vorticity conservation. Except for this local exception, the STF and SAF remain less than 1 degree away from their climatological path across the entire basin in the assimilation run.

\section{- Polar Front}

Figure 6 shows that in the climatology, the Polar Front (PF) enters the domain through Drake Passage, steers northwards above the North Scotia Ridge, follows the northern flank of the Maurice Ewing Bank and then takes a rather zonal route around 49S towards the eastern boundary. This front is located at its climatological position in the free model run west of $50 \mathrm{~W}$, but then takes a zigzagging path to the north above the North Scotia Ridge. It remains south of the Maurice Ewing Bank and continues towards the eastern boundary 2-3 degrees south of its climatological latitude. Between $50 \mathrm{~W}$ and the eastern boundary, the assimilation procedure successfully brings the PF northwards, close to its climatological position (see also Section 3c). The PF is locally deviated northwards around $5 \mathrm{~W}$, following the unrealistic artifact mentioned in the mean SSH field in Section 2b. However, the front quickly converges to its climatological position downstream.

To summarize, data assimilation significantly improves the location of the three main fronts all across the basin, despite a few local exceptions. Assimilation is particularly beneficial in the Confluence region, even though the BC leaves the coast more sharply than suggested by the observations (Fig. 5). The absence of SSH assimilation here (masking along the shelf) probably contributes to this discrepancy. This suggests that the free model tendency to keep the BC attached to the shelf (see Penduff et al., 2001, 2002) is not completely compensated for by the assimilation procedure applied further east. Such unrealistic model tendencies contribute to explain the increase in model-data misfit in the course of a 10-day forecast.

\section{- Snapshot of SSH}

Figure 7 shows snapshots of SSH on June 29, 1995 from the free run, the assimilated dataset and the assimilated run (forecast taken 10 days after the previous analysis). As mentioned previously, the model without assimilation produces Agulhas Rings that all have the same sign (anticyclones) and follow similar trajectories. Five to six Agulhas Rings are present in the free run at this date. This field is very different from that reconstructed from the mean SSH field and T/P+ERS SLA observations at that time (middle panel in Fig. 7). In the real ocean, about ten Agulhas Rings are present at that 


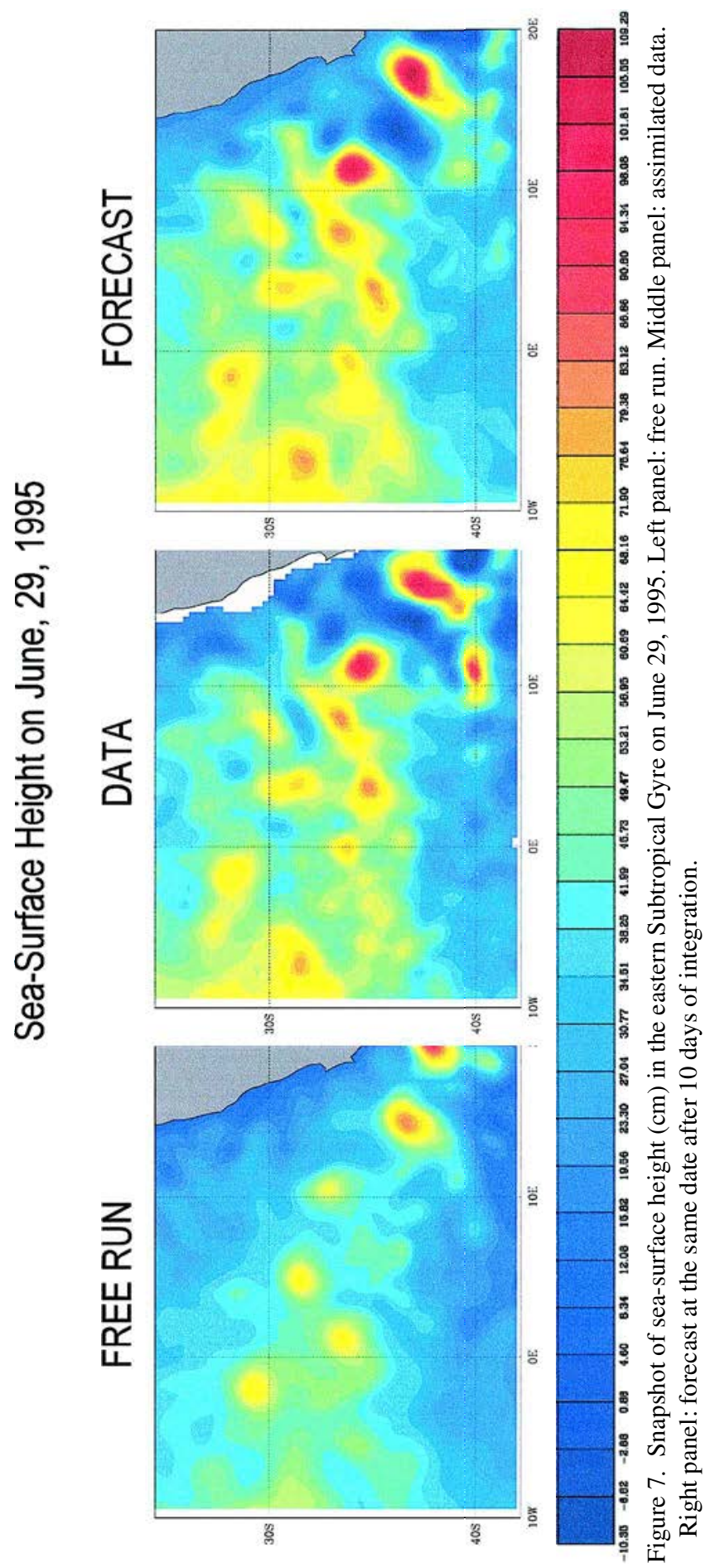



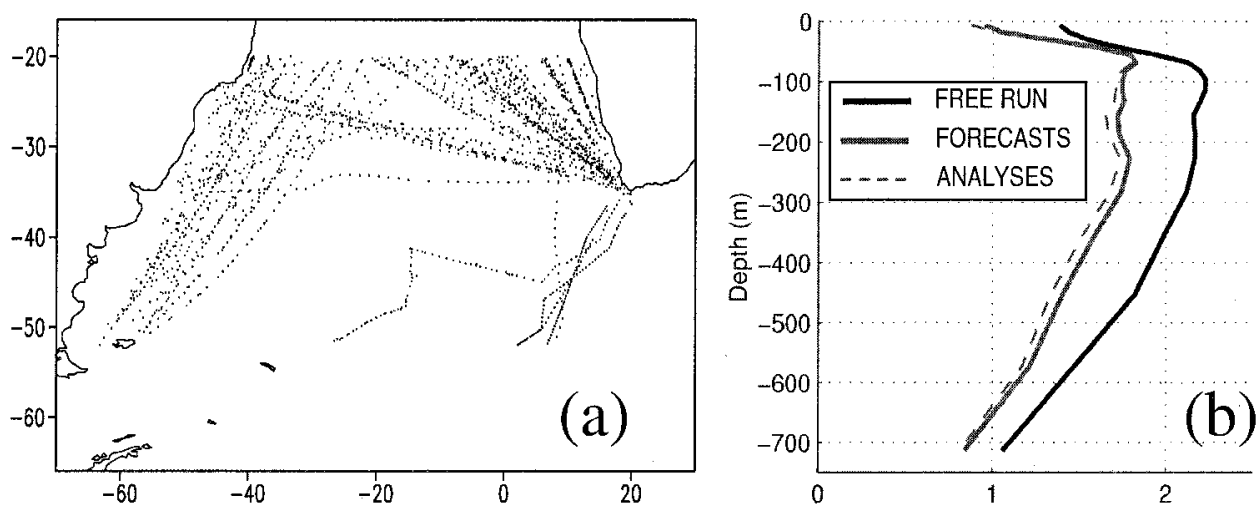

Figure 8. (a) Distribution of available XBT data in the assimilation area between 1993 and 1996. This data set was not assimilated in the model. (b) RMS misfit (degrees C) between XBT temperature profiles and their model counterparts interpolated at the same dates and locations, in the free run and in the assimilation run (analyses and forecasts).

time. They are dispersed meridionally, present further to the west and surrounded with cyclonic structures. All the mesoscale eddies (except one at 10E, 40S) and meanders observed that day from altimetry are present and well located in the model forecast, although their SSH signature is slightly weaker than observed. Despite this quantitative difference, probably due to the moderate resolution of the model, the system is able to control and properly forecast the horizontal distribution, structure, and evolution of mesoscale eddies over a long time.

\section{b. Temperature and salinity below the surface}

Figure 8-a shows the XBT lines where temperature profiles were collected in the domain between 1993 and 1996. This dataset is completely independent from the assimilated data, and thus constitutes a valuable reference for validation. The associated RMS misfit is evaluated by comparing XBT data with model temperatures at the same time and location. Figure 8-b shows that this misfit is decreased by $0.2-0.5 \mathrm{C}$ (about $20 \%$ ) near the surface and over the depth range 100-700 $\mathrm{m}$.

This latter diagnostic illustrates the improvement of the thermal structure in the upper ocean, but does not help to distinguish between the improvement in the phase of thermal transients and the improvement in the mean temperature field. Figure 9-a shows that the misfit between the 4-year averaged temperature field in the model and the RLMB annual climatology is decreased by $0.8 \mathrm{C}$ over the upper $400 \mathrm{~m}$, and by $0.1 \mathrm{C}$ at $2500 \mathrm{~m}$. This beneficial effect of assimilation reaches $3500 \mathrm{~m}$ for the mean temperature field and $700 \mathrm{~m}$ for the mean salinity field (Fig. 9-f), which is remarkable since only surface variables are assimilated. The difference between $\mathrm{T}$ and $\mathrm{S}$ probably comes from the better correlation of subsurface temperature than of subsurface salinity with assimilated surface variables (SSH, SST). As expected from the improvement in the position of the fronts, the 

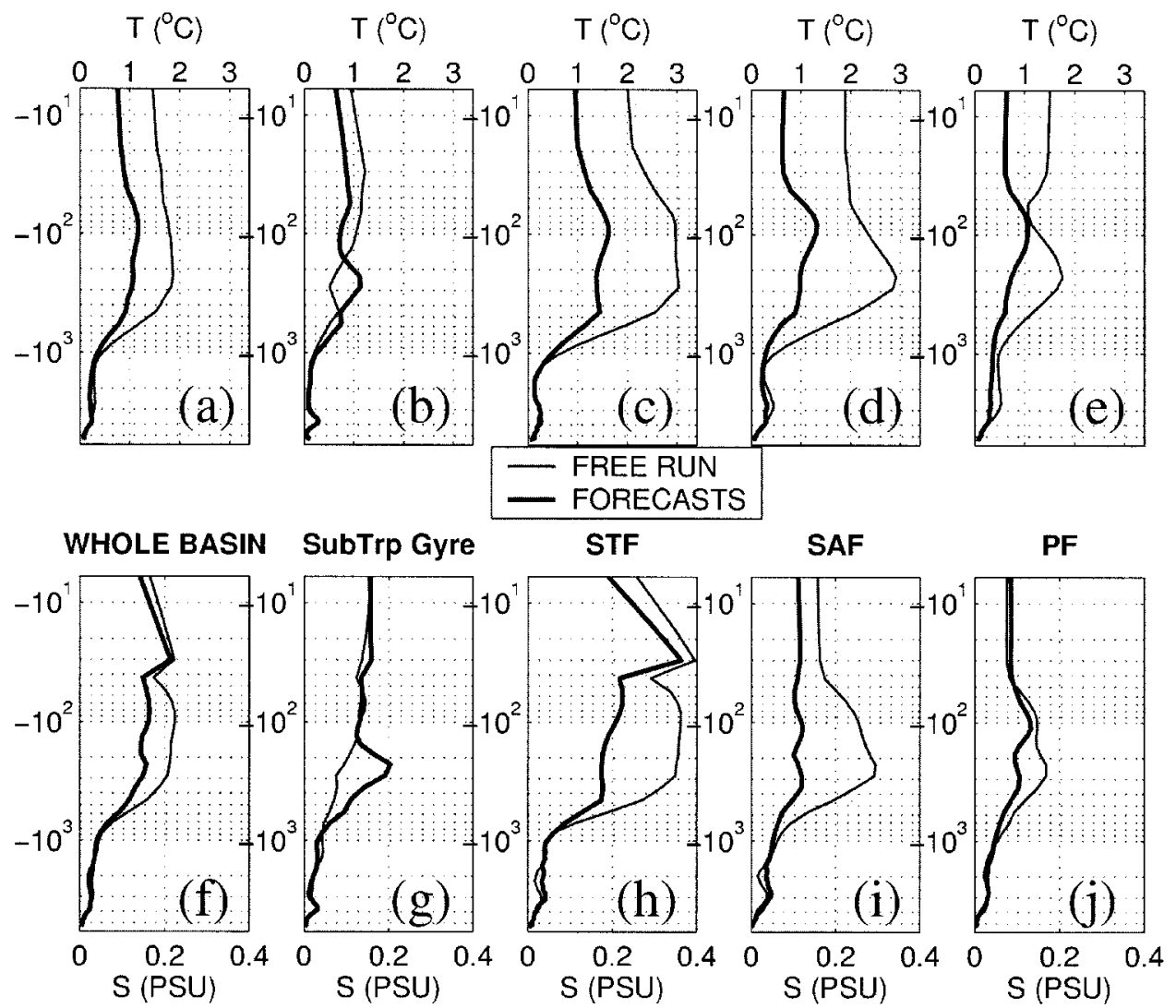

Figure 9. Area-averaged RMS misfits between the model tracer fields averaged over the period 1993-1996 and the RLMB annual climatology as a function of depth (m, log scale). Temperature on upper plots (a, b, c, d, e), salinity on lower plots (f, g, h, i, j). From left to right: averaged over the whole basin (a, f), in the bands 20-34S (b, g: Subtropical Gyre), 34-45S (c, h: STF), 42-52S (d, i: SAF), and 45-60S (e, j: PF). Areas STF, SAF and PF are shaded in Figure 6.

assimilation procedure very clearly improves the mean tracer fields along the SAF and STF (subdomains shown in Fig. 6) down to $1000 \mathrm{~m}$ (Figs. 9-c, d, h, i). Along the PF, the assimilation procedure improves the time-averaged temperature field in the depth range 0-3500 $\mathrm{m}$ and the time-averaged salinity field in the depth range 50-1000 $\mathrm{m}$ (Figs. 9-e, j). The horizontal distribution of salinity at $872 \mathrm{~m}$ is discussed in section 3.3. Data assimilation has a slight adverse effect on the mean tracer field in the Subtropical Gyre below the surface (band 20-34S, Figs. 9-b, g). This discrepancy might be due to the use of an EOF basis based on the model variability (rather than on errors, as should be done in theory) to propagate the surface information downwards. The truncation of the EOF basis might also induce spurious correlations between surface and subsurface variables, especially in this highly stratified region where correlations across the thermocline are naturally weak and 
thus more likely to be distorted by our simple statistical model. Nevertheless, the assimilation reduces the misfit between model temperatures and XBT data (Fig. 8), which are particularly abundant in this latitude band. This suggests that the phase of the thermal transients, mainly associated with the Agulhas Rings there, is significantly improved north of $34 \mathrm{~S}$.

Figure 10 shows the beneficial impact of assimilation on the mean salinity and velocity fields in the Confluence region down to about $1500 \mathrm{~m}$. The free run exhibits a salty southward-flowing Brazil Current attached to the shelf, while in the assimilated run the fresh and relatively shallow Malvinas Current realistically flows northwards, inshore of the Brazil Current. Further east, the distribution and properties of Antarctic Intermediate Waters (AAIW, located by the salt minimum around $400-500 \mathrm{~m}$ ) are also largely improved by the assimilation, even though the AAIW remains slightly below its climatological depth and the warm thermocline waters located above remain a bit thicker than in the climatology. At around $2500 \mathrm{~m}$, the North Atlantic Deep Water (NADW) advected to this latitude by the Deep Western Boundary Current appears more salty in the assimilation run than in the climatology and in the free run. Despite these small differences, this plot confirms the ability of the assimilation system to substantially improve the mean oceanic state in this dynamically complex region.

\section{c. Barotropic and subsurface circulation}

The barotropic streamfunction averaged over the period 1993-1996 is shown in Figure 11 for the free and assimilated runs (forecasts). The transport of the ACC (140 Sv) is the same in both runs. The part of it that flows directly eastwards south of South Georgia is decreased by $25 \%$ by the assimilation procedure ( $45 \mathrm{~Sv}$ instead of 60 ). More water thus flows northwards west of South Georgia in the assimilation run $(96 \mathrm{~Sv}$ instead of 80 without assimilation). This transport is closer to recent estimates $(129+/-21 \mathrm{~Sv}$, Arhan $e t$ al., 2002) even though it is still too weak. Most of this northward flow steers eastwards along the North Scotia Ridge, and does not significantly increase the transport of the Malvinas Current, which decreases from about $65 \mathrm{~Sv}$ at $48 \mathrm{~S}$ to about $35-40 \mathrm{~Sv}$ at $46 \mathrm{~S}$ in both runs. This transport remains smaller than the $70 \mathrm{~Sv}$ estimated by Peterson et al. (1992) at this latitude. More realistically, the Malvinas current brings cold waters further northward with assimilation.

The transport of the Brazil Current increases southwards through recirculations in both runs but is stronger with assimilation. It exceeds $70 \mathrm{~Sv}$ at $37 \mathrm{~S}$ (compared 50-55 Sv in the free run), in good agreement with the estimate by Peterson and Stramma (1991). The assimilation process generates a permanent anticyclone around $(53 \mathrm{~W}, 45 \mathrm{~S})$. This permanent feature, also present in sigma-coordinate model solutions without assimilation (de Miranda et al., 1999; Béranger, 2000; Penduff et al., 2001), is the signature of warm eddies coming southward from the Brazil Current that are blocked along the Falkland escarpment. The assimilation procedure thus improves the model solution in the Argentine basin with respect to the separation of the Brazil Current from the shelf, the location of the SAF and 

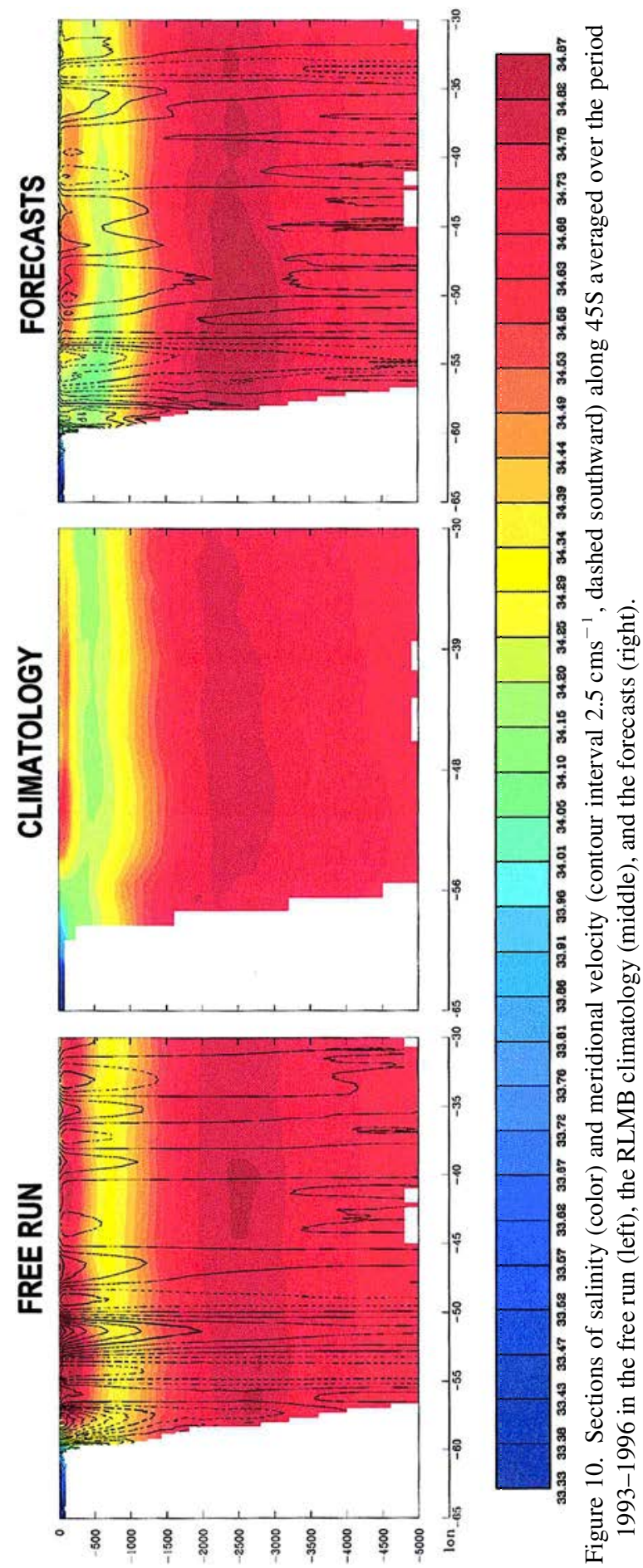

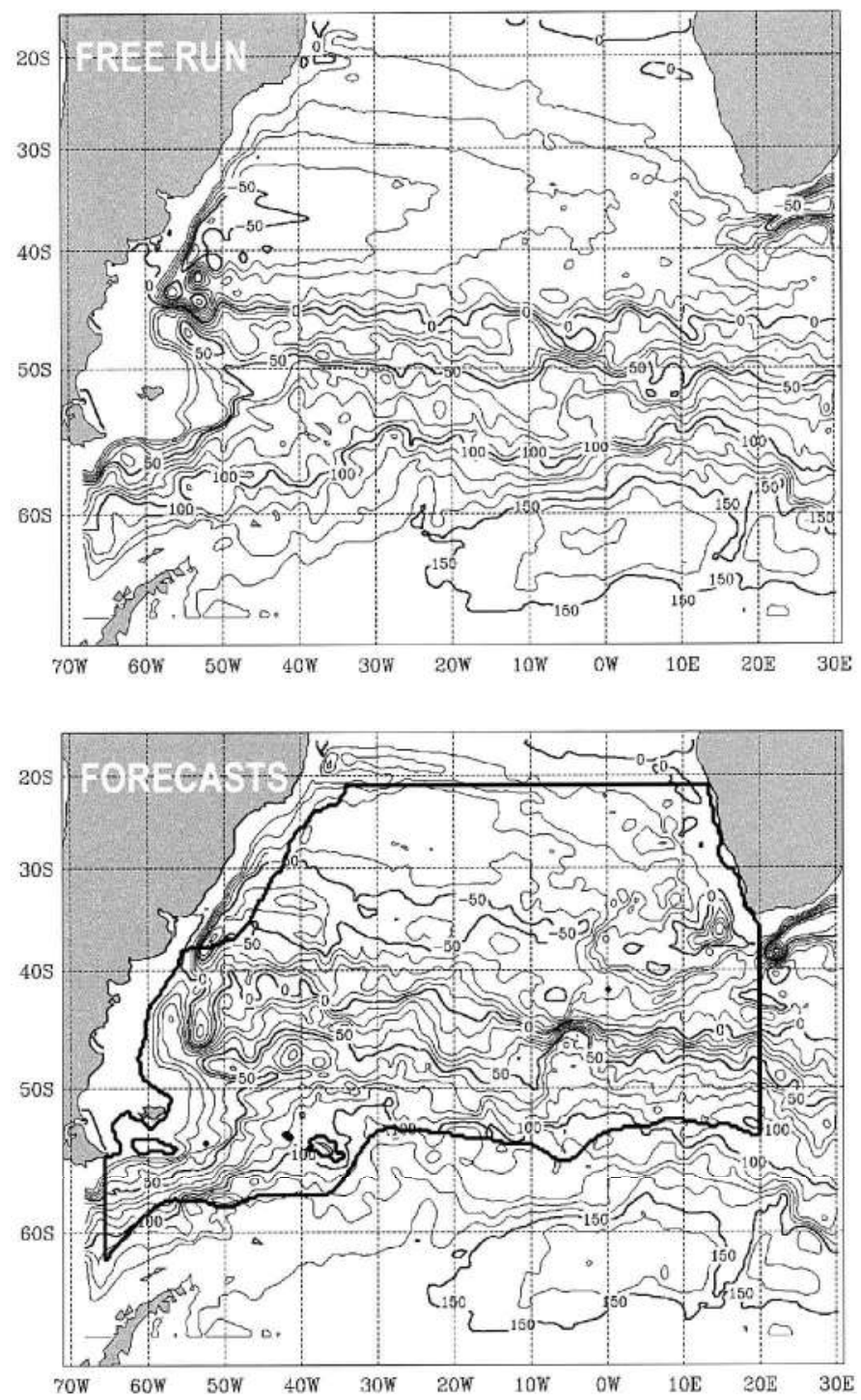

Figure 11. Barotropic streamfunction $\psi$ (in Sverdrups) averaged over the period 1993-1996 in the free run (upper panel) and the assimilated run (lower panel). Contour interval is $10 \mathrm{~Sv}$, areas of anticyclonic circulation $(\psi<0)$ are shaded. The area of SSH assimilation is superimposed.

STF, and the eddy flow (see section 3.4). However, the Zapiola anticyclone, a strong, permanent, barotropic circulation observed around $(45 \mathrm{~W}, 45 \mathrm{~S})$ is not present in Figures 10 and 11. de Miranda et al. (1999) and Penduff et al. (2001, 2002) suggest that the representation of topographic slopes in geopotential-coordinate models like the one used here leads to a misrepresentation of eddy-topography interactions that build up this 
permanent feature. The present results lend credence to this idea, since the assimilation, which improves the representation of the mean and eddy flows in this area, does not generate any anticyclonic circulation, even at depth. The transport of the Agulhas Current is almost the same in both runs: indeed, it is largely constrained by the eastern boundary, and assimilation is not fully performed east of $20 \mathrm{E}$. However, the assimilation enhances the retroflection cell by $40 \mathrm{~Sv}$ at $(22 \mathrm{E}, 38 \mathrm{~S})$, creates a cyclonic circulation in the Cape Basin, and a $\mathrm{C}$-shaped barotropic structure wrapped around the latter at the southeastern corner of the Subtropical Gyre. Data are too sparse to verify whether the intensity of these structures is realistic. Again, it is interesting to note that these assimilation results tend towards quite realistic sigma-coordinate solutions obtained at the same resolution without assimilation (Béranger, 2000; Penduff et al., 2001). This is the case not only in the Agulhas region (significant Agulhas Current recirculation cell, cyclonic circulation in the Cape Basin, $\mathrm{C}$-shape pattern northwest of it), but also in other regions (realistic overshoot of the Malvinas Current, relatively strong transport above the North Scotia Ridge, standing anticyclone west of Zapiola Drift, SAF and STF paths). The features added by the assimilation process and mentioned above may thus be physically consistent, and not artifacts of the method.

The mean velocity field at $872 \mathrm{~m}$ is shown in Figure 12 for the free and assimilation runs, along with the mean salinity field which exhibits marked meridional gradients at this intermediate depth. The RLMB climatological salinity, which is not assimilated in the model, is shown at the same depth for comparison. The beneficial impact of the assimilation on velocity and salinity fields appears clearly, especially in the southern part of the domain. The 5-degree northward shift of the PF allows the salty Surface Circumpolar Waters located south of it reach more realistic latitudes. The salinity front associated with the SAF also tends towards its climatological location (further north), and salinity values in the Confluence region between the STF and SAF are decreased toward more realistic, "subtropical" values (lower than 34.35). Even at depth, the assimilation procedure leads to substantial improvements in the simulated circulation and the tracer fields.

\section{d. Eddyflow}

i. Sea-surface height variability. The middle panel in Figure 13 shows the average of annual SSH variances (noted $S S H^{\prime 2}$ hereafter) computed from the assimilated dataset (T/P+ERS1-2) over the years 1993-1996. Its mean value is $102 \mathrm{~cm}^{2}$, averaged over the area where SSH is assimilated. The most turbulent regions are found along the SAF and STF in the Confluence region, in the Agulhas region and Cape Basin where Agulhas Rings are produced and exported westward, and near the western boundary in the band 60-50S along the path of the Malvinas Current. High values of $S S H^{\prime 2}$ are generally expected to be aligned with the main fronts and it appears that the variances measured during these four years are well aligned with the climatological position of the SAF and STF. This shows a posteriori that the comparisons made previously between the position of the fronts in the RLMB climatology and in the model during this period were meaningful.

On average over the same area, the SSH variance simulated by the model without 

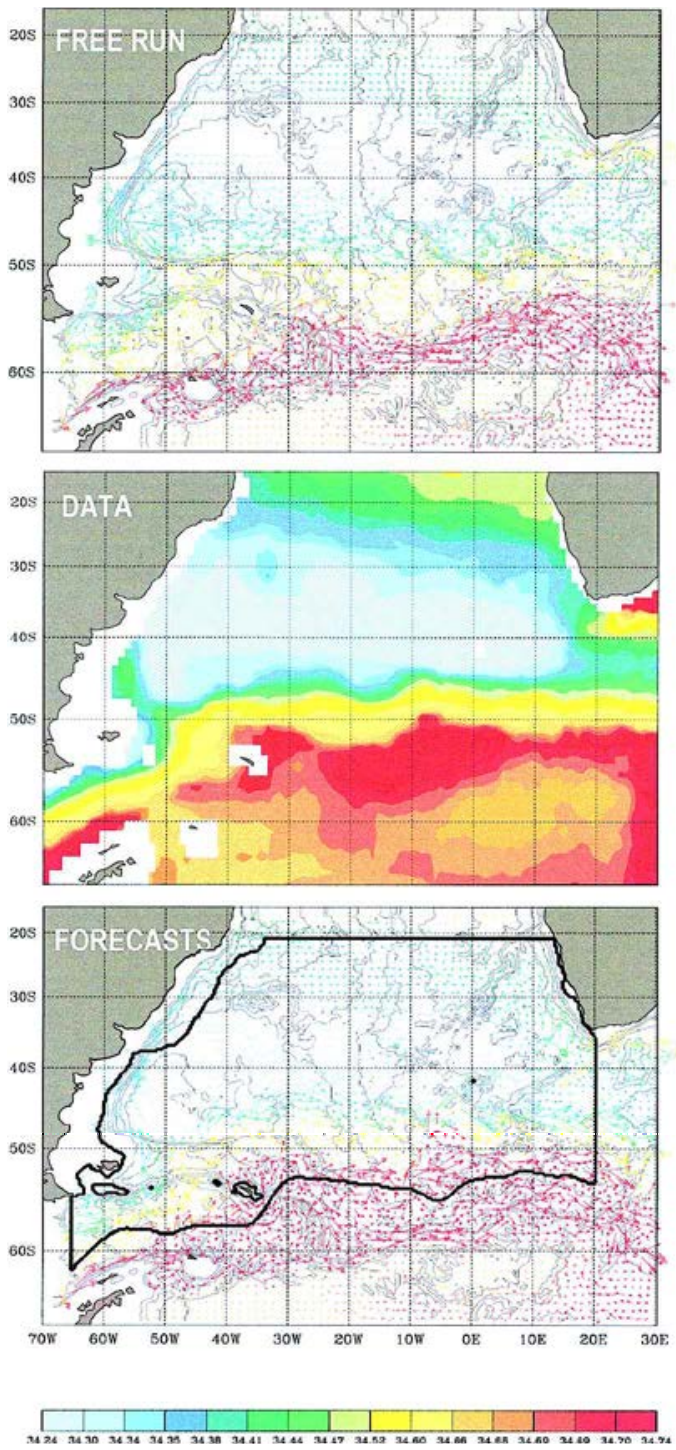

Figure 12. Upper panel: Topography (contours every $1000 \mathrm{~m}$ ), velocity (vectors) and salinity (colors) fields at $872 \mathrm{~m}$, averaged over 1993-1996 in the free run. Middle panel: Salinity at $872 \mathrm{~m}$ from the RLMB annual climatology. Lower panel: as the upper panel but in the assimilation run (forecasts). Only one vector in every four is shown; maximum velocities in the upper and lower panels are 35.4 and $43.9 \mathrm{~cm} \mathrm{~s}^{-1}$, respectively. The color scale is the same in the three panels. The area of SSH assimilation is superimposed.

assimilation (upper panel, Fig. 13) accounts for only $44 \%\left(45 \mathrm{~cm}^{2}\right)$ of the observed variance. It is also too weak along the path of the Malvinas Current in the free run. The observed C-shape pattern is not reproduced in the Confluence region where the STF and 

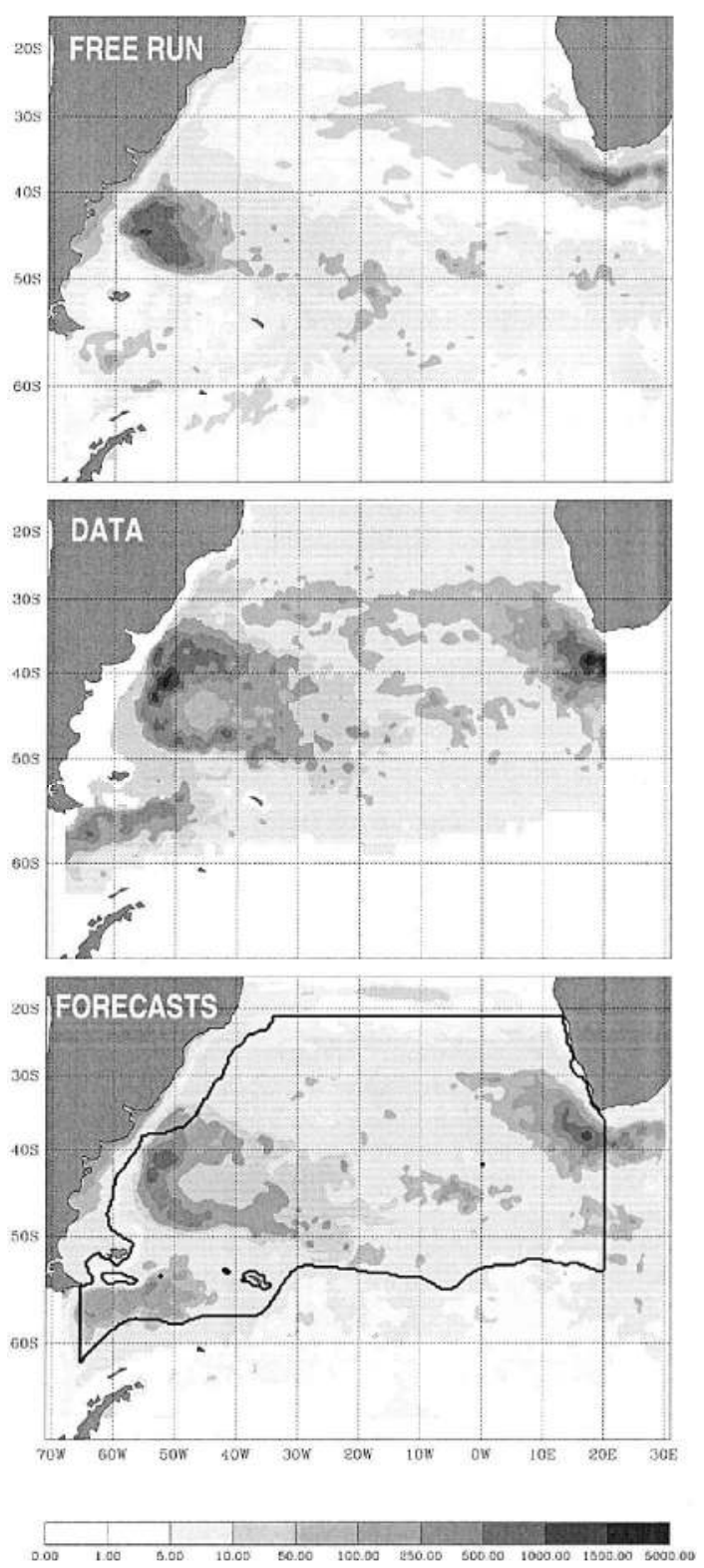

Figure 13. Sea-surface height variance $\left(\mathrm{cm}^{2}\right)$ over the period 1993-1996 in the free run (upper panel), the assimilated data (middle panel), and the forecasts (lower panel). The shading scale is the same in the three panels. The area of SSH assimilation is superimposed.

SAF are not well separated, and the maximum variance associated with the westward drift of the Agulhas Rings is too narrow in the Cape Basin because all the rings follow similar trajectories without meridional spreading. 
The assimilation procedure increases the horizontally-averaged SSH variance by $42 \%$ up to $64 \mathrm{~cm}^{2}$ ( $63 \%$ of the observed). As expected from the more realistic location of the $\mathrm{SAF} / \mathrm{STF}$ system, the horizontal distribution of turbulence is considerably improved in the Confluence region where the observed C-shaped pattern is well reproduced (but with a smaller intensity), a more realistic eddy activity is found in the Brazil Current between $30 \mathrm{~S}$ and 40S and in the Malvinas Current south of 50S along the western boundary. With assimilation, the Agulhas Rings spread meridionally in a more realistic way and the associated SSH variability is significantly enhanced in the Cape Basin.

Downstream of the Agulhas region, however, the zonal band of high SSH variance visible along $30 \mathrm{~S}$ in the free run and in the assimilated data is absent from the assimilated solution. This seems surprising since the assimilation scheme should a priori maintain the realistic features of the free run instead of eroding them. In the free run, however, individual Agulhas Rings are not in phase with observed ones even though they are statistically well located according to $S S H^{\prime 2}$. The assimilation procedure tends to erode out-of-phase rings and to create (or strengthen) in-phase rings since the corrections are proportional to SSH/SST misfits. Because the model-filter system is not perfect (i.e. limited resolution, linear and constant EOFs), assimilated rings are somewhat "too weak": their signature on individual SSH/SST fields, and ultimately on the $S S H^{\prime 2}$ field (lower panel of Fig. 13), remains weaker than observed. To summarize, the forecasted mesoscale activity is a bit weaker than observed throughout the basin (possibly weaker than in the free run in some regions), but mesoscale features are located where observed and evolve in phase with the real ocean (see Fig. 7) over the four years of assimilation. The use of a higher-resolution model and of a more sophisticated assimilation technique would certainly help strengthening the forecasted individual eddies, and further enhance the eddy intensity throughout the domain.

ii. Vertical distribution of eddy kinetic energy. The surface eddy kinetic energy (EKE) and $S S H^{\prime 2}$ fields are closely linked by the geostrophic balance. Both exhibit very similar horizontal distributions and highlight areas of strong mesoscale variability. We now estimate the impact of the assimilation procedure on EKE at depth. Since the horizontal distribution of EKE is qualitatively the same at all depths, the subsurface EKE field will be described by vertical profiles $\operatorname{EKE}(z)$. In-situ estimates of $\operatorname{EKE}(z)$ were computed from WOCE current meter measurements grouped into 6 clusters (Table 1). These estimates are compared with their model counterparts at the same locations, with and without assimilation (Fig. 14). Penduff et al. (2002) have shown that with respect to current meter data, the present model (forced climatologically, without assimilation) produces EKE fields that are too baroclinic and too weak in the band $30-35 \mathrm{~S}$. In the free run, indeed, $\operatorname{EKE}(z)$ is too weak over most areas. The impact of assimilation on the EKE at depth proves beneficial with the exception of the ACC cluster and, to a lesser extent, the Agulhas cluster (all or some moorings of which are located outside the area where assimilation is fully performed). In the 4 other clusters, EKE is strongly enhanced and tends towards observed 
Table 1. Definition of the six WOCE current meter clusters. Rows 2-5 define the longitude and latitude bands that locate each cluster, and row 6 indicates the number of moorings available in each cluster (see Fig. 14).

Cluster $\quad \min l o n \max l o n \min l a t \quad \max$ lat Moorings

$\begin{array}{lrrllr}\text { West. Bound. Curr. 30S } & 47 \mathrm{~W} & 38 \mathrm{~W} & 32 \mathrm{~S} & 28 \mathrm{~S} & 11 \\ \text { Cape Basin } & 6 \mathrm{E} & 9 \mathrm{E} & 30 \mathrm{~S} & 30 \mathrm{~S} & 2 \\ \text { Rio Grande } & 29 \mathrm{~W} & 27 \mathrm{~W} & 35 \mathrm{~S} & 31 \mathrm{~S} & 5 \\ \text { Agulhas } & 15 \mathrm{E} & 23 \mathrm{E} & 42 \mathrm{~S} & 37 \mathrm{~S} & 8 \\ \text { Falklands } & 42 \mathrm{~W} & 34 \mathrm{~W} & 50 \mathrm{~S} & 47 \mathrm{~S} & 12 \\ \text { ACC } & 4 \mathrm{~W} & 6 \mathrm{E} & 60 \mathrm{~S} & 50 \mathrm{~S} & 4\end{array}$

values over the whole water column. $\operatorname{EKE}(z)$ profiles are particularly improved by the assimilation procedure in the Rio Grande and Western Boundary Current areas. The assimilation scheme thus propagates sea-surface fluctuations downwards very efficiently, although EKE values remain globally smaller than observed.

\section{Conclusion}

The present validation study has shown that the sequential assimilation of SST and SSH data into an eddy-permitting model of the South Atlantic Ocean over four years improves the realism of the model solution (mean circulation, mean tracer distribution, and mesoscale activity), not only on assimilated surface variables but also at depth. Available in-situ observations are significantly sparser in the South Atlantic than in the northern basin, so in addition to the more usual statistical evaluation of the assimilation performance we also referred to different types of independent data (XBTs, temperature/salinity climatology, direct transport estimates, current meter measurements) to validate the model solution from different points of view.

Our assimilation method is a simplified version of a reduced-order multivariate Kalman filter, where the EOF base is held constant during the assimilation period. More innovative is the use of local EOFs which maximize the impact of high-resolution data and propagate the surface information towards the ocean depths in accordance with local vertical covariances diagnosed from the free run.

At the surface, the misfit between assimilated data and the model forecasts is globally reduced by $50 \%$. The mean position of the main fronts, the current system in the Confluence region, the horizontal distribution and intensity of the surface height variability are also significantly improved. Within the upper $700 \mathrm{~m}$, the misfit between model temperatures and independent synoptic XBT data is decreased by $20 \%$. The model temperature (T) and salinity (S) fields, averaged over the period 1993-1996, were shown to tend toward the RLMB climatology, down to $3500 \mathrm{~m}$ for $\mathrm{T}$ and $700 \mathrm{~m}$ for S. A direct comparison of the model solution with this climatology also revealed a clear improvement of the distribution of the main fronts and of water masses down to around $900 \mathrm{~m}$. 

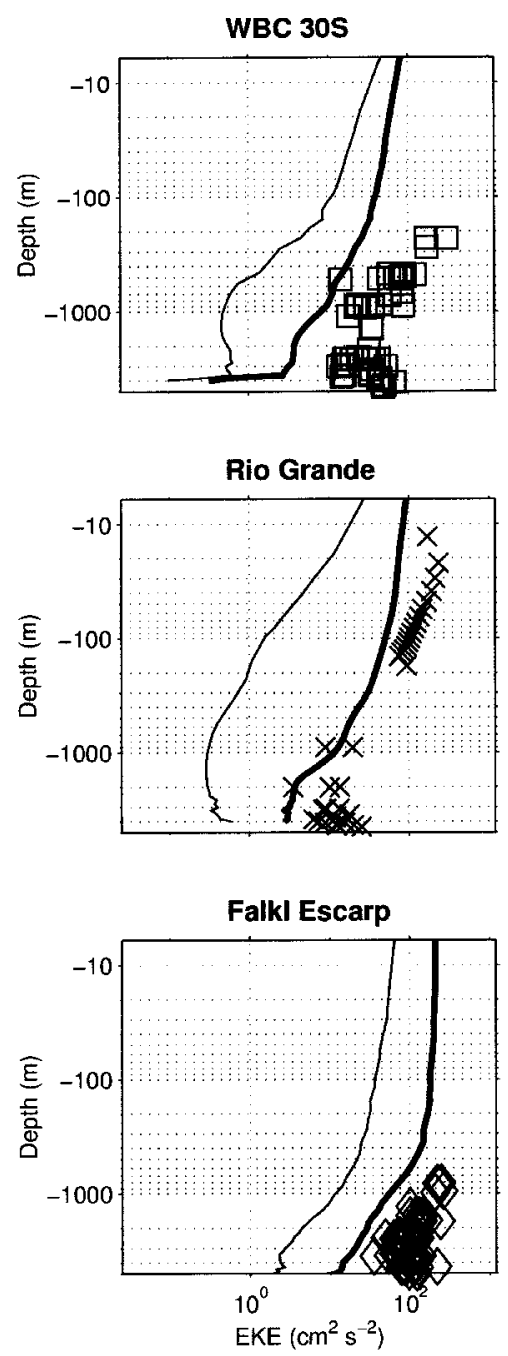
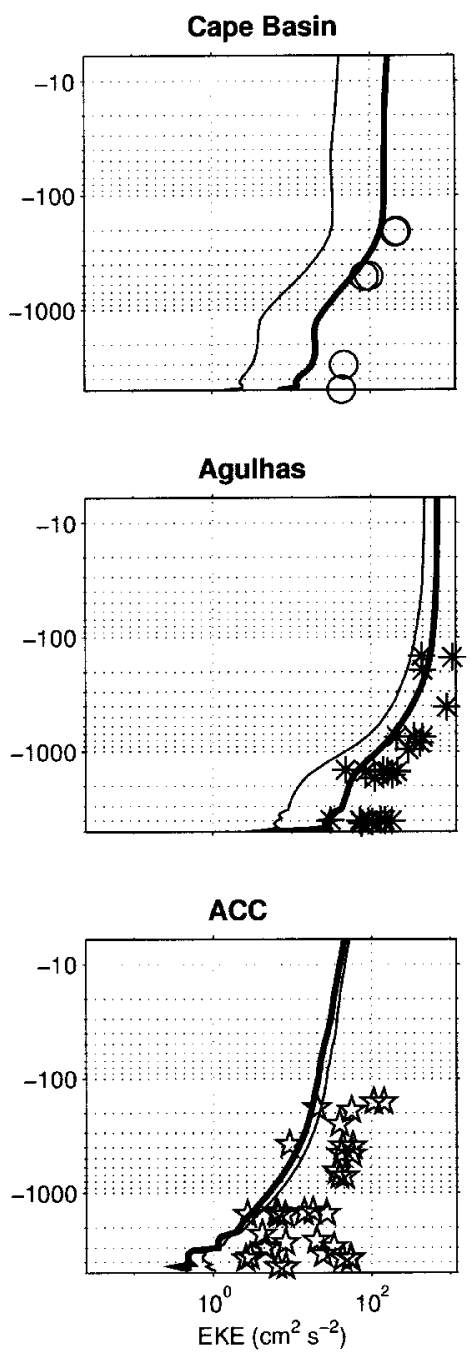

Figure 14. Vertical distribution of EKE $\left(\mathrm{cm}^{2} \mathrm{~s}^{-2}\right)$ from available WOCE current meter data (marks) and from the model (lines) at the same locations. Thin and thick lines represent EKE profiles computed over the period 1993-1996 from the free run and the assimilated run (forecasts), respectively. Figure 1 exhibits the location of these WOCE moorings, organized in six clusters (see Table 1) corresponding to each panel. In-situ EKE measurements were computed from low-pass filtered (cutoff at 5 days) horizontal velocity time series to allow a comparison with model EKEs within each cluster. Model EKE profiles were computed at the same locations as individual WOCE moorings, and then averaged horizontally over the moorings available within each cluster.

The assimilation technique is able to control the evolution and trajectories of individual mesoscale structures and to bring the simulated eddy activity closer to the observations over the basin. The SSH variance is still lower than observed (for example along the 
Agulhas Rings pathway). The use of a more sophisticated assimilation method and of a higher resolution would help improve the representation of individual eddies and increase the basin-scale eddy activity. The enhancement of the eddy field is not confined near the surface. Subsurface eddy kinetic energy levels are increased by up to one order of magnitude and come close to available current meter estimates, throughout the water column.

Our analysis has revealed that the most adverse effect of assimilation is found on the mean temperature and salinity fields between 150 and $1000 \mathrm{~m}$ in the Subtropical Gyre (increase of the model-data misfit, see Fig. 9). Although the origin of this problem is uncertain, it is likely that the truncated EOF basis deduced from the free model variability introduces spurious correlations between observed and unobserved variables. Assimilation of additional subsurface in-situ data would certainly help control the solution below highly stratified thermoclines. Given satellite data and a good estimate of the mean sea-surface height, the present method is thus able to compensate for major model deficiencies and to improve many non-observed features of the undersampled South Atlantic Ocean. The combined use of an innovative local assimilation procedure, a high vertical resolution (42 levels) and full-depth multivariate local EOFs that represent well the links between surface and subsurface dynamics allows a consistent propagation of surface information toward non-observed and subsurface variables in most regions.

We believe that the validation of data assimilation experiments requires full-depth, multivariate investigations like the present one in addition with the more usual statistical validation. The present study is a prelude to a longer reanalysis of the South Atlantic circulation, and to a more detailed validation of the simulated seasonal to interannual variability (work currently underway). Validation of models results in general, and of assimilation results in particular, is difficult because of the lack of synoptic data. The next observational programs should encompass provision of the extra data that are necessary to go beyond the validation that has been shown here.

Acknowledgments. Most of this work was carried out at Laboratoire des Ecoulements Géophysiques et Industriels with the support of CNES (postdoctoral fellowship), CNRS, and IFREMER (grant URM 18). This article was written when TP was visiting the Center for Ocean-Atmospheric Prediction Studies (Florida State University). We are pleased to thank James J. O'Brien and William K. Dewar for insightful comments and financial support. Computational support was provided by the Institut du Développement et des Ressources en Informatique Scientifique (IDRIS). The authors are grateful to Jean-Michel Brankart and Jean-Marc Molines for their contribution to the development/tuning of the model and assimilation method, to the partners of the DIADEM/TOPAZ European Project who provided us with satellite data, to Pascal Legrand (LPO/IFREMER) for the mean SSH field, to Sébastien Grall and Katell Guizien for processing the WOCE current meter data, to Catherine Maillard (SYSMER/ IFREMER) and Laurent Debreu for providing the XBT database and associated validation tools. We acknowledge the constructive comments made by both reviewers. 


\section{REFERENCES}

Arhan, M., A. C. Naveira Garabato, K. J. Heywood and D. P. Stevens. 2002. The Antarctic Circumpolar Current between the Falkland Islands and South Georgia. J. Phys. Oceanogr., 32, 1914-1931.

Barnier, B. 1998. Forcing the Ocean, Ocean Modeling and Parameterization, E. P. Chassignet and J. Verron, eds., Kluwer Academic Publishers, The Netherlands, 45-80.

Béranger, K. 2000. Application d'une nouvelle formulation des conditions atmosphériques de surface pour la simulation de la circulation et des masses d'eau dans l'Océan Atlantique Sud. PhD thesis, Université J. Fourier, Grenoble, France.

Blanke, B. and P. Delecluse. 1993. Variability of the tropical ocean simulated by a general circulation model with two different mixed-layer physics. J. Phys. Oceanog., 23, 1363-1388.

Brasseur, P., J. Ballabrera and J. Verron. 1999. Assimilation of altimetric observations in a primitive equation model of the Gulf Stream using the steady-state limit of a singular evolutive extended Kalman filter. J. Mar. Syst., 22, 269-294.

de Miranda, A. P., B. Barnier and W. K. Dewar. 1999. On the dynamics of the Zapiola anticyclone.J. Geophys. Res., 104, 21,137-21,149.

Fu, L. L., I. Fukumori and R. N. Miller. 1993. Fitting dynamic models to Geosat sea-level observations in the tropical Pacific Ocean. Part II: A linear, wind driven model. J. Phys. Oceanogr., 23, 2,162-2,181.

Fukumori, I. and P. Malanotte-Rizzoli. 1995. An approximate Kalman filter for ocean data assimilation: an example with an idealized Gulf Stream model. J. Geophys. Res., 100, 6,7776,793 .

Gelb, A. 1974. Applied Optimal Estimation, MIT Press, Cambridge, MA, 374 pp.

Kalman, R. E. and R. S. Bucy. 1961. New results in linear filtering and prediction theory, Trans. ASME, J. Basic Eng., 95-108.

Le Grand, P., E. J. O. Schrama and J. Tournadre. 2003. An inverse estimate of the dynamic topography of the ocean. Geophys. Res. Lett., 30(2), 1062.

Le Traon, P. Y., F. Nadal and N. Ducet. 1998. An improved mapping method of multi-satellite altimeter data. J. Atmos. Oceanic Technol., 25, 522-534.

Lutjeharms, J. R. E. and D. J. Webb. 1995. Modelling the Agulhas Current System with FRAM (Fine Resolution Antarctic Model), Deep-Sea Res., 42, 523-551.

Madec, G., P. Delecluse, M. Imbard and C. Levy. 1998. OPA8.1 general circulation model reference manual, Notes de l'IPSL, Université Pierre et Marie Curie, B102 T15-E15, 4 place Jussieu, Paris Cedex 5, France, 11, 91 pp.

Penduff, T., B. Barnier, K. Béranger and J. Verron. 2001. Comparison of near-surfacemean and eddy flows from two numerical models of the South Atlantic Ocean. J. Geophys. Res., 16, 857-16,867.

Penduff, T., B. Barnier, M.-A. Kerbiriou and J. Verron. 2002. How topographic smoothing contributes to differentiating the eddy flows simulated by sigma- and $z$-level models. J. Phys. Oceanogr., 32, 122-137.

Peterson, R. G. 1992. The boundary currents in the western Argentine Basin. Deep-Sea Res., 39, 623-644.

Peterson, R. G. and L. Stramma. 1991. Upper level circulation in the South Atlantic Ocean, Prog. Oceanogr., 26, 1-73.

Pham, D. T., J. Verron and M. C. Roubaud. 1998. A Singular evolutive extended Kalman filter for data assimilation in oceanography.J. Mar. Syst., 16, 323-340.

Quartly, G. D. and M. A. Srokosz. 1993. Seasonal variations in the region of the Agulhas retroflection: studies with Geosat and FRAM. J. Phys. Oceanogr., 23, 2107-2124.

Reynaud, T., P. Legrand, H. Mercier and B. Barnier. 1998. A new analysis of hydrographic data in the Atlantic and its application to an inverse modelling study. WOCE Int. Newslett., 32, 29-31. 
Reynolds, R. W. and T. M. Smith. 1995. A high-resolution global sea-surface temperature climatology, J. Climate, 8, 1571-1583.

Smith, W. H. F. and D. T. Sandwell. 1997. Global seafloor topography from satellite altimetry and ship depth soundings. Science, 277, 1956-1962.

Tréguier, A.-M., T. Reynaud, T. Pichevin, B. Barnier, J.-M. Molines, A. P. de Miranda, C. Messager, J.-O. Beismann, G. Madec, N. Grima, M. Imbard, and C. Le Provost, 1999. The CLIPPER project: high resolution modeling of the Atlantic. Int. WOCE Newslett., 36, 3-5.

Verron, J., L. Gourdeau, D. T. Pham, R. Murtugudde and A. J. Busalacchi. 1999. An extended Kalman filter to assimilate satellite altimeter data into a nonlinear numerical model of the tropical Pacific Ocean: Method and validation, J. Geophys. Res., 104, 5,441-5,458. 